\title{
Psychology of Hair Loss Patients and Importance of Counseling
}

\author{
Lakshyajit Dhami ${ }^{1}$ \\ 1 Vasudhan Cosmetic \& Plastic Surgery Centre, Mumbai, Maharashtra, \\ India \\ Address for correspondence Lakshyajit Dhami, MS, MCh (Plastic \\ Surgery), Vasudhan Cosmetic \& Plastic Surgery Centre, Mumbai, \\ Indian J Plast Surg 2021;54:411-415. \\ Maharashtra 400092, India (e-mail: lakshyajitdhami@gmail.com).
}

\begin{abstract}
Keywords

- hair loss

- hair transplant

- counseling

- psychology

- body dysmorphic disorder

Androgenetic alopecia (AGA) is highly prevalent in society, affecting both men and women. More than the sociological meaning of hair loss, it has become a very important part of self-identity or "body image." A psychological concept of body image refers to one's thoughts, feelings, perceptions, and behavioral changes related to one's physical looks. In spite of alopecia's common occurrence, it often leads to psychological disturbance and distress. Hair thinning and perceived hair loss also has a very important negative impact on the psyche of the individual. The common emotional aspects associated are self-consciousness, embarrassment, frustration, and jealousy. Knowledge of these effects among the clinicians managing hair loss patients is beneficial. The clinician must make an active effort to identify the borderline group of patients with body dysmorphic syndrome so as to manage them with psychotherapeutic medication for their hair loss prior to hair transplantation. This article aims to provide important information and an understanding of how the psychology gets affected due to hair loss, particularly AGA and its management to the practicing hair transplant surgeons.
\end{abstract}

\section{Introduction}

Scalp hair has greater social and psychological significance as compared with its biological importance to mankind. Hair has no significant function in humans except providing some cranial padding and protection from the Sun's rays. ${ }^{1}$ Beyond its sociological meaning, hair can become an essential part of self-identity or "body image." Scalp hair always makes a statement. A head full of hair is perceived as a sign of gender, youthfulness, vigor, and status. Scalp hair is a unique part of the human body that can be altered and restyled as per one's desire. It can be colored, cut, and curled in a short period of time. In contrast, any transformation in other body parts would need substantial efforts and time, involve artificial adornments, or entail various surgical procedures.
The term "bad hair day" is an evidence to the psychological importance of hair. A person suffering from hair loss may experience a "bad hair day" every day. A patient with hair loss goes through multiple feelings and emotions due to personal and social pressure. Hair loss may cause psychological stress out of proportion to the problem. This is worsened by excessive advertisement of hair treatments and camouflage techniques in movies, on television, newspapers, and social media.

\section{The Impact of Hair Loss}

Loss of hair at an early age due to nonscarring androgenic alopecia (AGA) or pattern hair loss (PHL), results in a person feeling physically and socially less attractive, less virile, and

(c) 2021. Association of Plastic Surgeons of India. All rights reserved. This is an open access article published by Thieme under the terms of the Creative Commons Attribution-NonDerivative-NonCommercial-License, permitting copying and reproduction so long as the original work is given appropriate credit. Contents may not be used for commercial purposes, or adapted, remixed, transformed or built upon. (https://creativecommons.org/ licenses/by-nc-nd/4.0/)

Thieme Medical and Scientific Publishers Pvt. Ltd., A-12, 2nd Floor, Sector 2, Noida-201301 UP, India 
less likeable leading to low self-esteem. The severity of these symptoms will be directly related to the severity of AGA.

The psychological stress is felt more in women as compared with men. The hair is the crowning beauty and pride for a woman. She believes this adds to her feminity and attractiveness. Any sign can be traumatic to a woman's selfesteem and identity, especially when affected at a younger age. Hair loss also is perceived as early aging for older woman making them feel loss of sexual attraction and virility to their mate.

Women face increased societal pressure as compared with men due to reduced cosmetic acceptance. Hence, baldness will affect them more negatively and worsen their life situation.

The difference between emotions and psychology related to hair loss is that emotions are what a patient feels or experiences, and psychology is how the doctor perceives these emotions. The patient may feel sad or dejected but diagnosing him of depression is the doctor's job.

The emotions as a result of hair loss are sometimes so overwhelming that it starts affecting the patient's daily routine life. It may lead to limiting social activities, avoiding family occasions, and spending enormous amount of time and money on hair grooming. This behavioral impact is noticed not only in men but in women too. Studies by Hunt and McHale have shown that around $40 \%$ of women with alopecia have had marital problems and around 63\% claimed to have career-related issues. ${ }^{2}$

The same grade of alopecia may elicit a different psychological response in different individuals. Some will have a physiologically normal response, some may have a borderline psychosomatic disorder, while some may precipitate the underlying psychiatric disorder. Clinical studies have shown that 20 to $48 \%$ of patients presenting for cosmetic surgery may have a psychiatric diagnosis too. ${ }^{3}$

Some of the mild to severe symptoms of associated psychological problems with hair loss are: anxiety, anger, depression, embarrassment, decreased confidence, reduction in work and sexual performance, social withdrawal, and suicidal tendencies. These are similar to those usually seen with chronic and severe life-threatening diseases.

Alopecia areata is a chronic disease, in contrast to PHL, with an incidence of $2.1 \%$. It starts all of a sudden and causes hair loss with sharp and circular borders. ${ }^{4}$ Although the exact etiopathology is largely unknown; the factors known to play some role in its development are: genetic, immunological, environmental, infectious, or psychological. Alopecia areata and its significant effect on the quality of life in relation to psychological factors has been studied in more details. ${ }^{4}$ Alopecia areata patients as compared with other individuals are also reported to be more commonly affected with social and family problems and they have reduced capacity to cope with events.

Trichotillomania is a disorder that involves impulsive, recurrent, and irresistible urges to pull out hair from scalp, eyebrows, and other body part. It is a disorder, characterized by chronic hair pulling and leads to a negative effect on the quality of life not only of the patient but also their family members. This condition is primarily an obsessive compulsive psychiatric disorder. Although it can easily be diagnosed by the history and patient examination, patients usually avoid reporting their problem due to shame and fear of being mocked or being labeled as a lunatic. The surgeon should therefore approach the behavior in a nonincriminating or noncondescending manner and should be extra careful while referring these patients to the psychiatrist.

\section{Disorders Associated with Hair Loss}

Scarring alopecia is a pathological condition characterized by loss of hair as a result of fibrosis of the follicular structure. Whatever may be the underlying reason, the psychological effect of scarring alopecia is usually more than nonscarring alopecia.

Hair loss-related mental disorders can be broadly divided in to:

Adjustment disorder, which may depend on the severity of hair loss, and personality disorder, which is psychopathological and may be hypochondriacal or body dysmorphic disorder (BDD).

Patient with hypochondriac disorder becomes preoccupied and obsessed with the fear of serious illness, even when they do not have any abnormality, due to wrong interpretation of normal body functions. Medical investigations to rule out any pathology and counseling also do not relieve their symptoms. Psychologic pseudo-effluvium is classic example of this disorder, which usually affects at middle age and continues till old age.

\section{Body Dysmorphic Disorder}

BDD is a mental health disorder in which a patient cannot stop thinking about one or more perceived defects or flaws in their appearance-a flaw that appears minor or cannot be seen by others. It usually starts during adolescence with 16 years old as an average age of diagnosis. ${ }^{5}$ Like many other mental health conditions, BDD may result from a combination of causes such as genetic predisposition, abuse or bullying during childhood, low self-esteem, fear of being alone or isolated, and perfectionism or competing with others. If a person's unhappiness with body part increases to the level that it starts to affect the daily routine or causes significant emotional disturbances, they are diagnosed with BDD. ${ }^{6}$ These patients have difference in visual processing. They tend to see themselves differently from how other people look at them. The common signs and symptoms of BDD are:

- Excessive concern for physical appearance.

- Person has obsessive compulsive behavior like either looking at self again and again or totally avoids looking at self and try to keep the body part covered with makeup of clothing.

- Keep thinking, worrying, and asking about their concern throughout the day.

- Avoid social gathering, public places, schools, or workplace. 
- Emotional distress and suicidal tendencies.

- History of previous cosmetic procedures and unsatisfied with it.

- History of previously visiting several doctors for the correction of same defect.

- Patient who has come with the same problem earlier, without ever deciding about treatment.

- Coming for consultation with detailed description of some celebrity's appearance (more often with their photos) and asking for results to match it and occasionally coming with a detailed procedure plan for the surgeon to carry it out.

- Patient who is looking for surgical results without any side effects or scarring.

Despite very high prevalence of psychological ailment among patients seeking treatment for hair loss, some of these remain undiagnosed and/or are untreated in a clinical practice. The clinician being aware of these problems is the first step in their management.

Most of the patients who seek treatment for hair loss have an underlying emotion or a motive and this is purely a physiological reason to look better, so far as their perceived self-image is concerned. Their behavior, obsession, desire, and demands are based with this goal in mind. If this patient has realistic expectations and is self-motivated, the hair transplant procedure will benefit the patient, not only physically but also emotionally. While a small group of patients who have psychological or psychosomatic causes will neither be happy or satisfied nor benefit in any way with the best possible surgical outcome. They need to be counseled and treated for these ailments before undertaking their hair transplant surgery.

\section{Questionnaire to Identify or Rule Out Body Dysmorphic Disorder}

A general questionnaire ( - Table $\mathbf{1}$ ) which the patients are requested to fill themselves and the clinician later analyzes it during consultation, if need be with the help of the patient's relative.

Please note that the questions in $\boldsymbol{- T}$ Table $\mathbf{1}$ are intended to screen for BDD and not diagnose it. The answers indicated can suggest that BDD may be present and evaluation by a psychiatrist is recommended to determine the accurate diagnosis and its management. The surgeon should work in a formalized collaboration with a psychiatrist so that it is easier for the patient to accept psychiatric evaluation and therapy without much resistance. They may be required to be treated with psychopharmacological and behavioral therapy, if indicated. If they are left undiagnosed and untreated and are still operated upon, there is a very high chance that these patients may not be satisfied. They may even sue the doctor or become aggressive or violent and physically harm the doctor.

It is of primary importance to be able to identify borderline BDD patients or mild cases of obsessive compulsive disorder (OCD), as the patients at either end of this scale will be easily identifiable by any hair transplant surgeon
Table 1 Questionnaire to identify or rule out body dysmorphic disorder (BDD) ${ }^{7}$

\begin{tabular}{|c|c|c|}
\hline $\begin{array}{l}\text { Sr. } \\
\text { No. }\end{array}$ & Question & Score \\
\hline 1 & \multicolumn{2}{|c|}{$\begin{array}{l}\text { How often do you deliberately check your feature(s)? } \\
\text { Not accidentally catch sight of it. Please include } \\
\text { looking at your feature in a mirror or other reflective } \\
\text { surfaces like a shop window or mobile or looking at it } \\
\text { directly or feeling it with your fingers. }\end{array}$} \\
\hline$A$ & About 40 times or more a day & 8 \\
\hline B & About 20 to 40 times a day & 6 \\
\hline C & About 10 to 20 times a day & 4 \\
\hline $\mathrm{D}$ & About 5 to 10 times a day & 2 \\
\hline$E$ & Never check & 0 \\
\hline 2 & \multicolumn{2}{|c|}{$\begin{array}{l}\text { To what extent do you feel your feature(s) are cur- } \\
\text { rently ugly, unattractive or 'not right'? }\end{array}$} \\
\hline$A$ & Very ugly or "not right" & 8 \\
\hline B & Markedly unattractive & 6 \\
\hline C & Moderately unattractive & 4 \\
\hline $\mathrm{D}$ & Slightly unattractive & 2 \\
\hline $\mathrm{E}$ & Not at all unattractive & 0 \\
\hline 3 & \multicolumn{2}{|c|}{$\begin{array}{l}\text { To what extent does your feature(s) currently cause } \\
\text { you a lot of distress? }\end{array}$} \\
\hline A & Not at all distressing & 0 \\
\hline B & Slightly distressing & 2 \\
\hline $\mathrm{C}$ & Moderately distressing & 4 \\
\hline $\mathrm{D}$ & Markedly distressing & 6 \\
\hline$E$ & Extremely distressing & 8 \\
\hline 4 & \multicolumn{2}{|c|}{$\begin{array}{l}\text { How often does your feature(s) currently lead you to } \\
\text { avoid situations or activities? }\end{array}$} \\
\hline A & Always avoid & 8 \\
\hline B & Avoid about $3 / 4$ of the time & 6 \\
\hline $\mathrm{C}$ & Avoid about half of the time & 4 \\
\hline $\mathrm{D}$ & Avoid about $1 / 4$ of the time & 2 \\
\hline $\mathrm{E}$ & Never avoid & 0 \\
\hline 5 & \multicolumn{2}{|c|}{$\begin{array}{l}\text { To what extent does your feature(s) currently preoc- } \\
\text { cupy you? That is, you think about it a lot and it is hard } \\
\text { to stop thinking about it? }\end{array}$} \\
\hline$A$ & Not at all preoccupied & 0 \\
\hline B & Slightly preoccupied & 2 \\
\hline C & Moderately preoccupied & 4 \\
\hline $\mathrm{D}$ & Very preoccupied & 6 \\
\hline $\mathrm{E}$ & Extremely preoccupied & 8 \\
\hline 6 & \multicolumn{2}{|c|}{$\begin{array}{l}\text { If you have a partner, to what extent does your feature } \\
\text { (s) currently have an effect on your relationship with } \\
\text { an existing partner? (e.g., affectionate feelings, } \\
\text { number of arguments, enjoying activities together). If } \\
\text { you do not have a partner, to what extent does your } \\
\text { feature(s) currently have an effect on dating or de- } \\
\text { veloping a relationship? }\end{array}$} \\
\hline$A$ & Not at all & 0 \\
\hline
\end{tabular}

(Continued) 
Table 1 (Continued)

\begin{tabular}{|c|c|c|}
\hline $\begin{array}{l}\text { Sr. } \\
\text { No. }\end{array}$ & Question & Score \\
\hline$B$ & Slightly & 2 \\
\hline C & Moderately & 4 \\
\hline D & Markedly & 6 \\
\hline$E$ & Extremely & 8 \\
\hline 7 & \multicolumn{2}{|c|}{$\begin{array}{l}\text { To what extent does your feature(s) currently interfere } \\
\text { with your ability to work or study, or your role as a } \\
\text { homemaker? (Please rate this even if you are not } \\
\text { working or studying: we are interested in your ability } \\
\text { to work or study.) }\end{array}$} \\
\hline A & Not at all & 0 \\
\hline$B$ & Slightly & 2 \\
\hline C & Moderately & 4 \\
\hline $\mathrm{D}$ & Markedly & 6 \\
\hline$E$ & Very seriously: I can't work & 8 \\
\hline 8 & \multicolumn{2}{|c|}{$\begin{array}{l}\text { To what extent does your feature(s) currently interfere } \\
\text { with your social life? (with other people, e.g., parties, } \\
\text { pubs, clubs, outings, visits, home entertainment). }\end{array}$} \\
\hline A & Not at all & 0 \\
\hline$B$ & Slightly & 2 \\
\hline C & Moderately & 4 \\
\hline $\mathrm{D}$ & Markedly & 6 \\
\hline$E$ & Very severely & 8 \\
\hline 9 & \multicolumn{2}{|c|}{$\begin{array}{l}\text { To what extent, do you feel your appearance is the } \\
\text { most important aspect of who you are? }\end{array}$} \\
\hline A & Not at all & 0 \\
\hline$B$ & Slightly & 2 \\
\hline C & Moderately & 4 \\
\hline $\mathrm{D}$ & Mostly & 6 \\
\hline $\mathrm{E}$ & Totally & 8 \\
\hline
\end{tabular}

Note: A general questionnaire which the patients are requested to fill themselves and the clinician later analyzes it during consultation, if need be with the help of the patient's relative.

Scores analysis:

- Higher scores reflect greater distress and interference in patient's life and the likelihood of a diagnosis of BDD.

- If the score is 40 or more, it is recommended that patient seek an assessment, as he/she is likely to have BDD.

- If the score is between 30 and 40, patient may still have BDD and will still benefit from an assessment.

- It is unlikely to have BDD if the score is below 30.

- It is advisable repeat the questionnaire at any time during treatment to see if there are any changes in the symptoms.

without any psychiatric expertise or experience. Borderline cases or mild cases of OCD or BDD may also benefit with surgical procedures or a combination of psychiatric and hair transplant treatments. Such patients may refuse to get psychiatric help initially and counseling and communication skills of hair transplant surgeon are of utmost importance in such instances. It is the surgeon's responsibility to act as a psychotherapist and explain the complexity of the condition to the patient. Only after the patient has an insight, will he be willing to accept the change. Such patients should never be accepted for surgery in the first visit. There was a study conducted which shows that hair loss patients who display BDD-like concerns, benefit significantly in their personal and social life and also in work performance after hair transplantation. $^{8}$

Cognitive behavioral approaches and medications have been found to be effective treatment for BDD in controlled studies. Hair restoration surgery shall only be considered after the effective BDD treatment. ${ }^{6}$

\section{Counseling of Hair Loss Patient}

During consultation it is important to make the patient understand that:

- Not every type of hair loss can be treated.

- The medical line of treatment may or may not be able to partially restore some hair loss that happened as a result of AGA, but the treatment is more likely to prevent further hair loss.

- It may take 3 to 6 months before you see the results from these treatments.

- No one line of treatment will work for everybody, not even in two patients with a similar type of hair loss.

- Sometimes hair loss is stubborn and may require trying different modalities including hair transplant surgery, before finding the one that may work.

- AGA/male and female PHL seen at an early age and treated by hair transplantation would need a long-term medical line of treatment to prevent hair loss and more likely will need multiple sessions over a period of time, in case of age-related progressive hair loss.

- Even after successful hair transplantation, the full growth may take 6 months to 1 year, during which period the patient may need to use concealers.

- In patients with progressive or advanced hair loss with restricted donor hair, there may be a need to use an adjuvant concealer along with hair transplantation.

- In patients with severe PHL and inadequate donor area the only remedy that may help would be a hair patch or a wig or the patient may accept and maintain a shaved look.

\section{Conclusion}

An ideal case to perform a successful hair transplant procedure is the one with no obvious psychopathology, clearly defined areas of dissatisfaction, realistic expectations, and the one who is self-motivated.

Conflict of Interest

None declared.

\section{References}

1 Cash TF. The psychology of hair loss and its implications for patient care. Clin Dermatol 2001;19(02):161-166

2 Hunt N, McHale S. The psychological impact of alopecia. BMJ 2005;331(7522):951-953 
3 Napoleon Anthony. The presentation of personalities in plastic surgery. Annals of Plastic Surgery 1993;31(03):193-208

4 Gokalp H. Psychological aspect of hair loss. In: Kutlubay Z, Serdaroglu S, eds. Hair and Scalp Disorders. Chapter 13. London, UK: IntechOpen; 2017:239-252

5 Mysore V. Psychological aspects of hair loss; Chapter 15. In: Hair Transplantation. New Delhi, India: Jaypee Brothers Medical Publishers (P) Ltd.; 2016:92-98
6 True R, Garg A, Garg S. Body dysmorphic disorder and other psychological aspects of hair loss; Chapter 18. In: The Practical Guide to Hair Transplantation. Noida, India: Thieme Medical and Scientific Publishers Pvt Ltd.; 2021:355-361

7 Accessed December 9, 2021 at: http://www.bddfoundation.org

8 Rajput R. Evaluation of body dysmorphic disorder in hair loss patients and benefit after hair transplant. Acta Medica International. 2015;2(01):111-116 